\title{
NUEVA TERMINAL DEL AEROPUERTO DE BARCELONA - ESPAÑA
}

\author{
(THE NEW AIRPORT TERMINAL IN BARCELONA - SPAIN)
}

Ricardo Bofill

Fecha de recepción: 13-1.92

Taller de Arquitectura

\section{RESUMEN}

Ante la saturación y falta de diseño unitario y actualizado del Aeropuerto de Barcelona se aborda la remodelación del antiguo edificio terminal. La situación de los antiguos elementos de edificación, condiciona la solución lineal de la misma.

Una calle elevada es la espina dorsal del edificio que al modo de las Ramblas de Barcelona ofrecen comercios, kioscos, etc.

Los otros nuevos elementos de edificación son los módulos de preembarque y la terminal de Internacional.

Los primeros tienen una galería acristalada en su perimetro: una división transparente que permite separar los flujos de llegadas y salidas.

La nueva terminal, se apoya sobre cuatro grandes columnas, y está dotada de un doble acristalamiento en todo su perímetro.

\section{SUMMARY}

The lack of integral and modernized design and the saturation of the Barcelona Airport made the remodelling of the old terminal building necessary. The old building elements conditioned the lineal solution in the remodelling.

An elevated street forms the backbone of the building which, like the Ramblas in Barcelona, has shops, news stands, etc.

Other new elements are the pre-boarding modules and the International terminal.

The former have a glazed gallery in their perimeter: a transparent division which allows the separation of the arrival and departure flows.

The new terminal rests on four large columns and has double glazing in the entire perimeter.

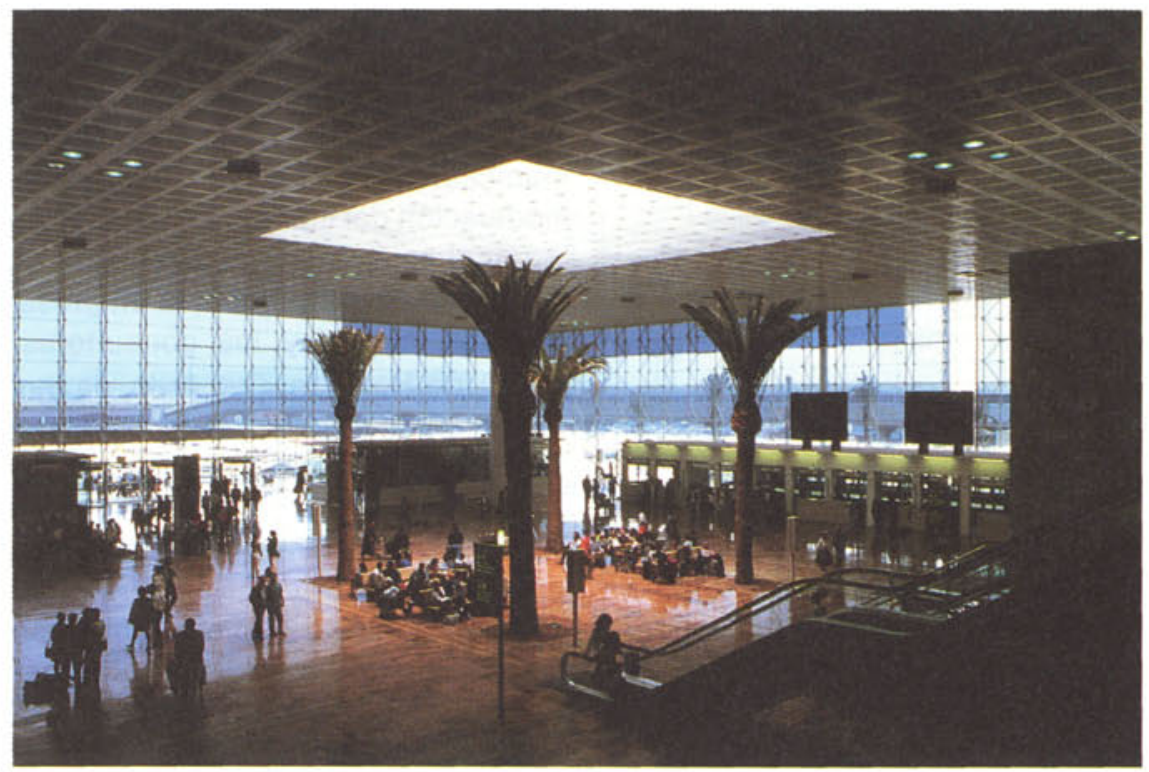




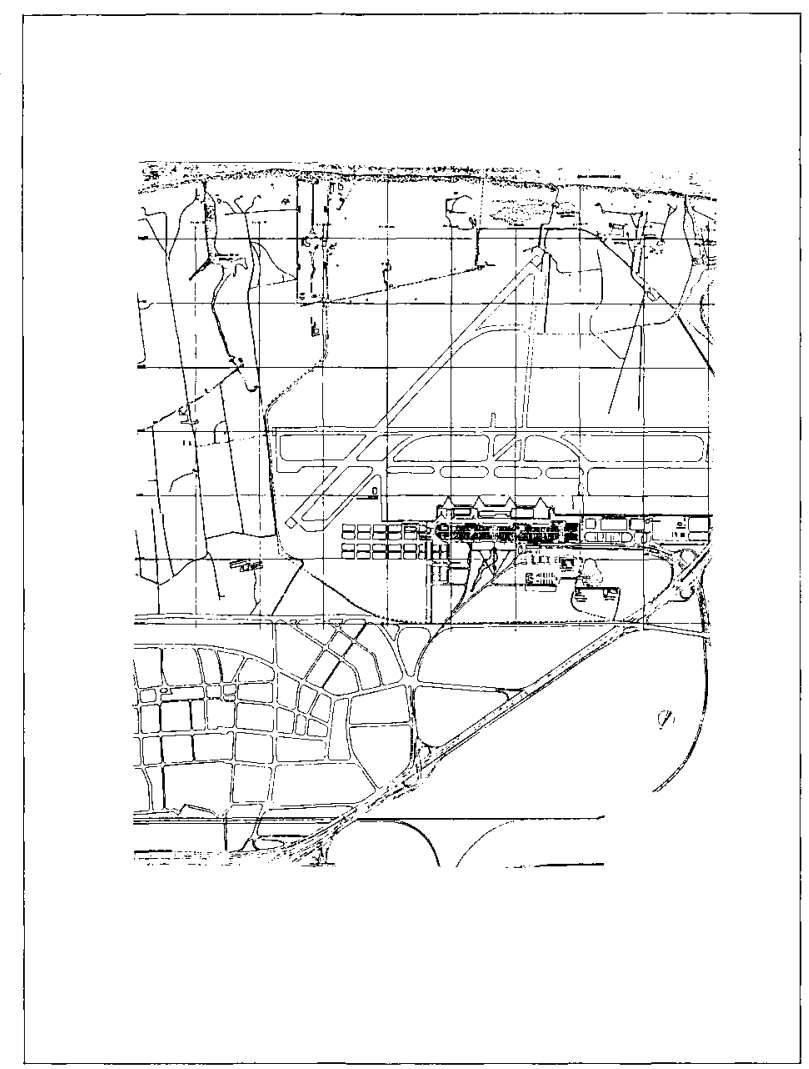

Situación

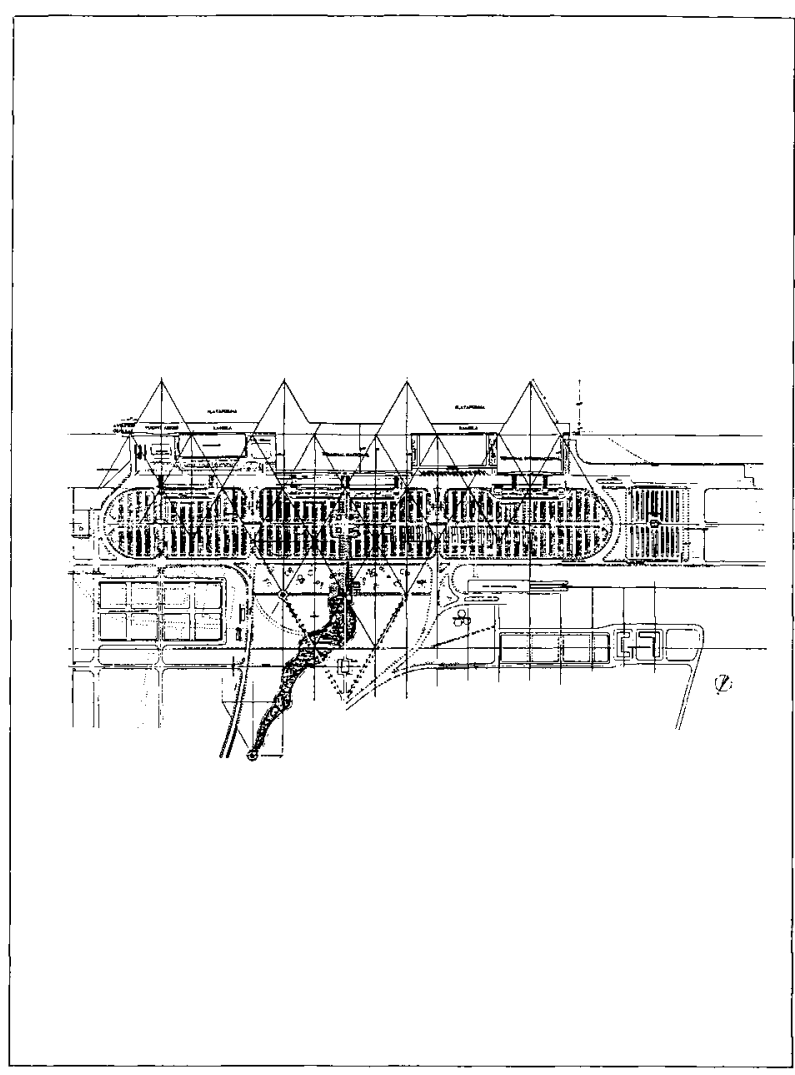

El diseño de un aeropuerto es especialmente importante si se tiene en cuenta que se trata de la primera imagen que recibe el visitante que llega a la ciudad. En este momento, en que la imagen de Barcelona y de España cambia y se orienta hacia una mayor calidad de vida, el aeropuerto necesita ser un ejemplo de esta realidad.

En un aeropuerto existen dos zonas claramente definidas:

- el lado tierra, con todos los servicios y facilidades para los pasajeros, y

- el lado aire, es decir, la pista de aterrizaje y los servicios técnicos de mantenimiento de los aviones.

La función básica de un aeropuerto es permitir el contacto entre tierra y aire con el máximo de comodidad, tanto para los pasajeros como para las aeronaves, condición que no puede cumplir en la actualidad el aero. puerto de Barcelona.

Ante la situación de incomodidad, saturación y falta de un diseño unitario y actualizado del Aeropuerto de Barcelona, el Ministerio de Transportes, Turismo y Comunicaciones ha decidido emprender las obras de remodelación del edificio terminal. El proyecto de nueva terminal está siendo realizado por el Taller de Arquitectura de Ricardo Bofill, la empresa española de ingeniería Intecsa y los consultores especializados NACO, de Holanda, Ove Arup, de Inglaterra, y con la colaboración de diversos especialistas en los campos de iluminación, hormigón, etc.

El objetivo que tiene que cumplir la remodelación del aeropuerto es básicamente permitir una mayor afluencia de pasajeros y aviones garantizando una máxima comodidad. Se ha previsto poder pasar de 6.000 .000 de pasajeros al año en la actualidad a una cifra de 12.000.000, aumentar la capacidad de estacionamiento de aeronaves de 34 a 62 , de los cuales 24 en posición de contacto a través de los fingers. 


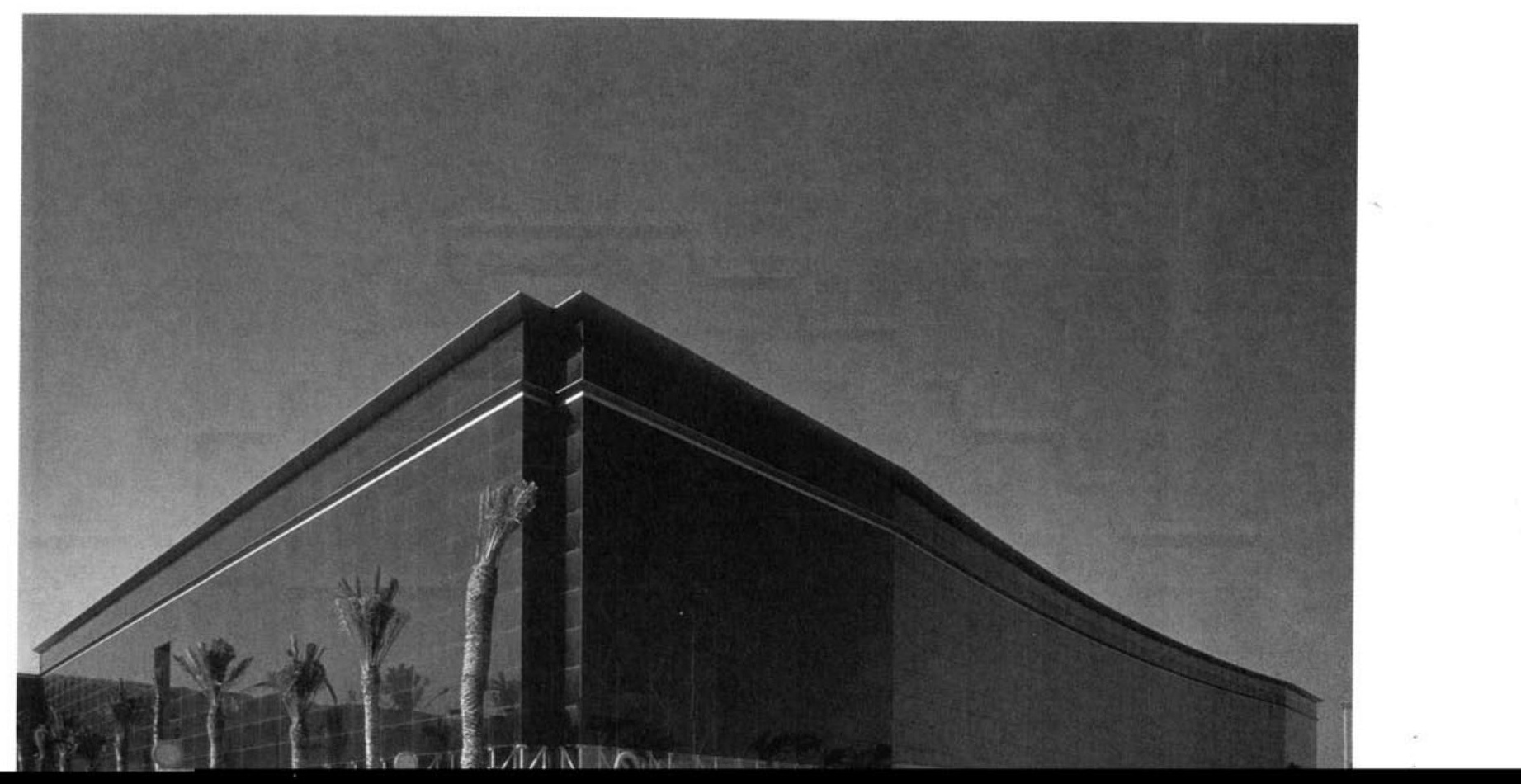




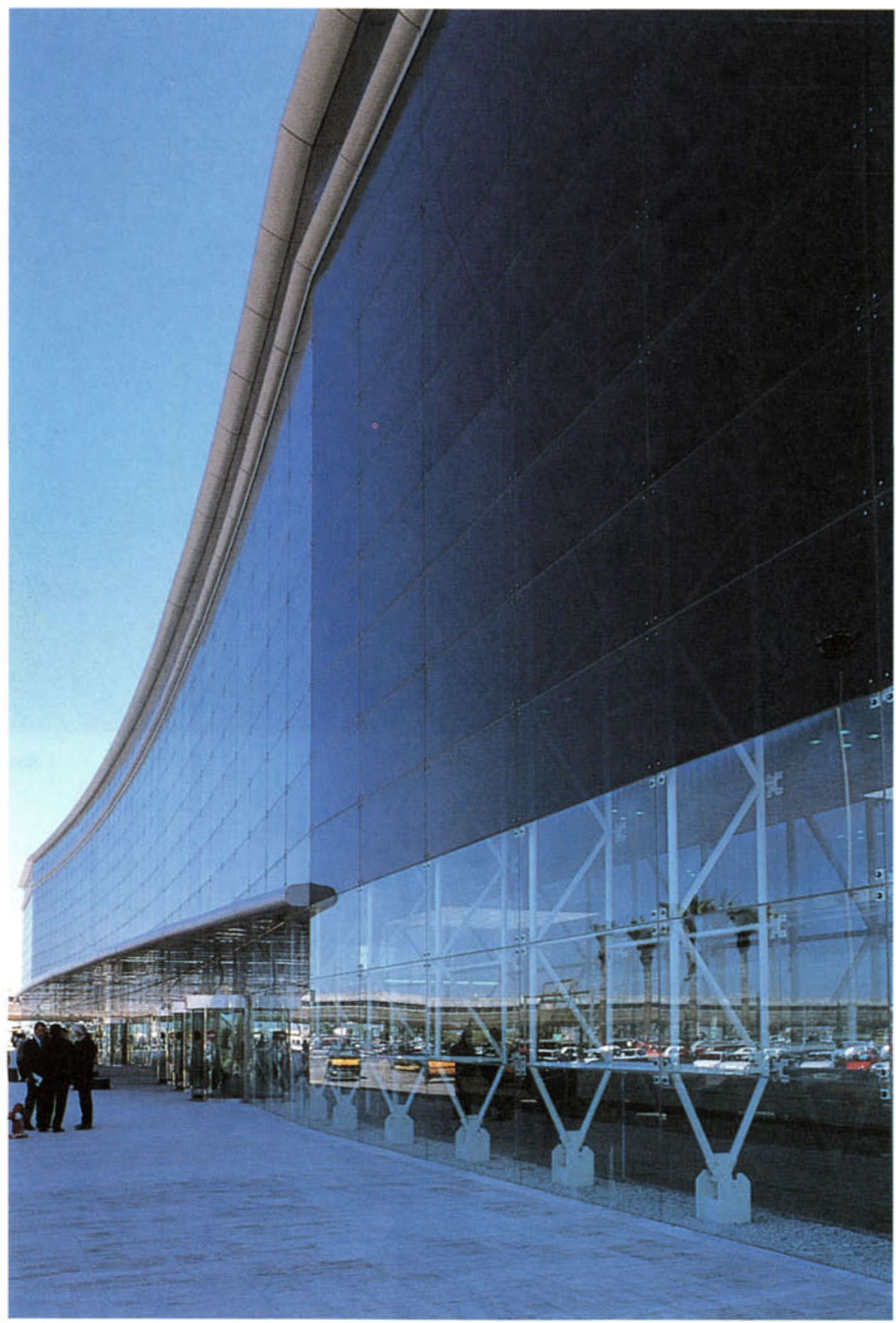


Informes de la Construcción, Vol. 43 n. 417 , enero/febrero, 1992

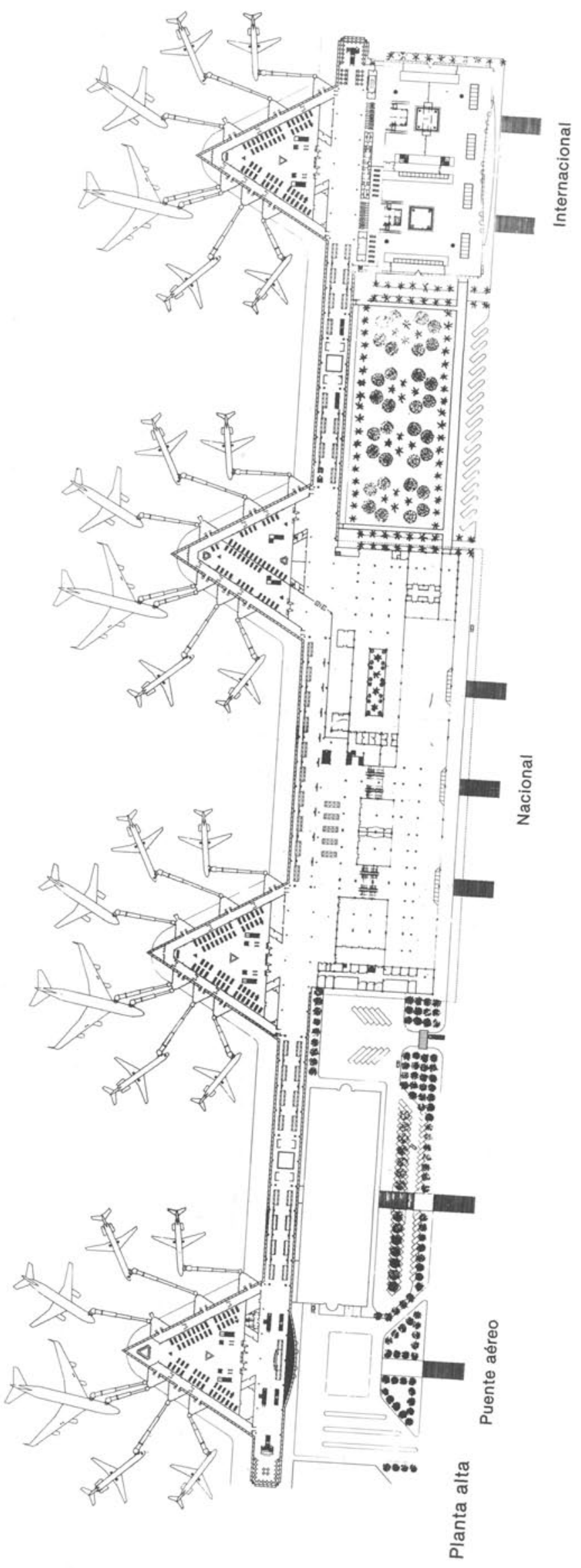

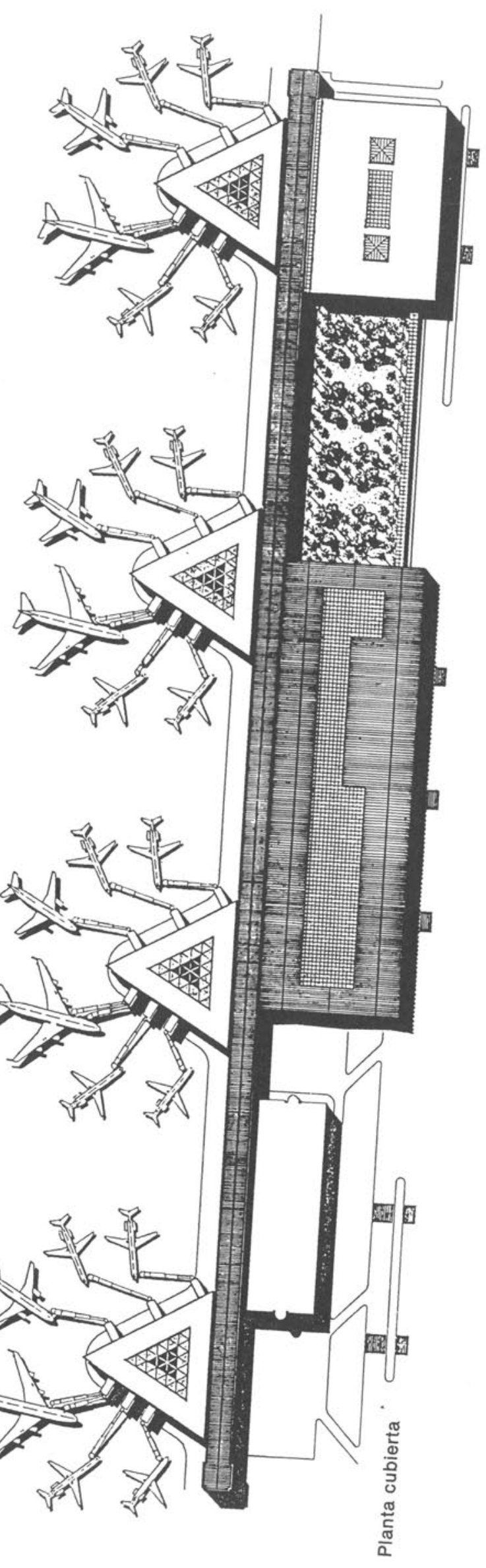

http://informesdelaconstruccion.revistas.csic.es 


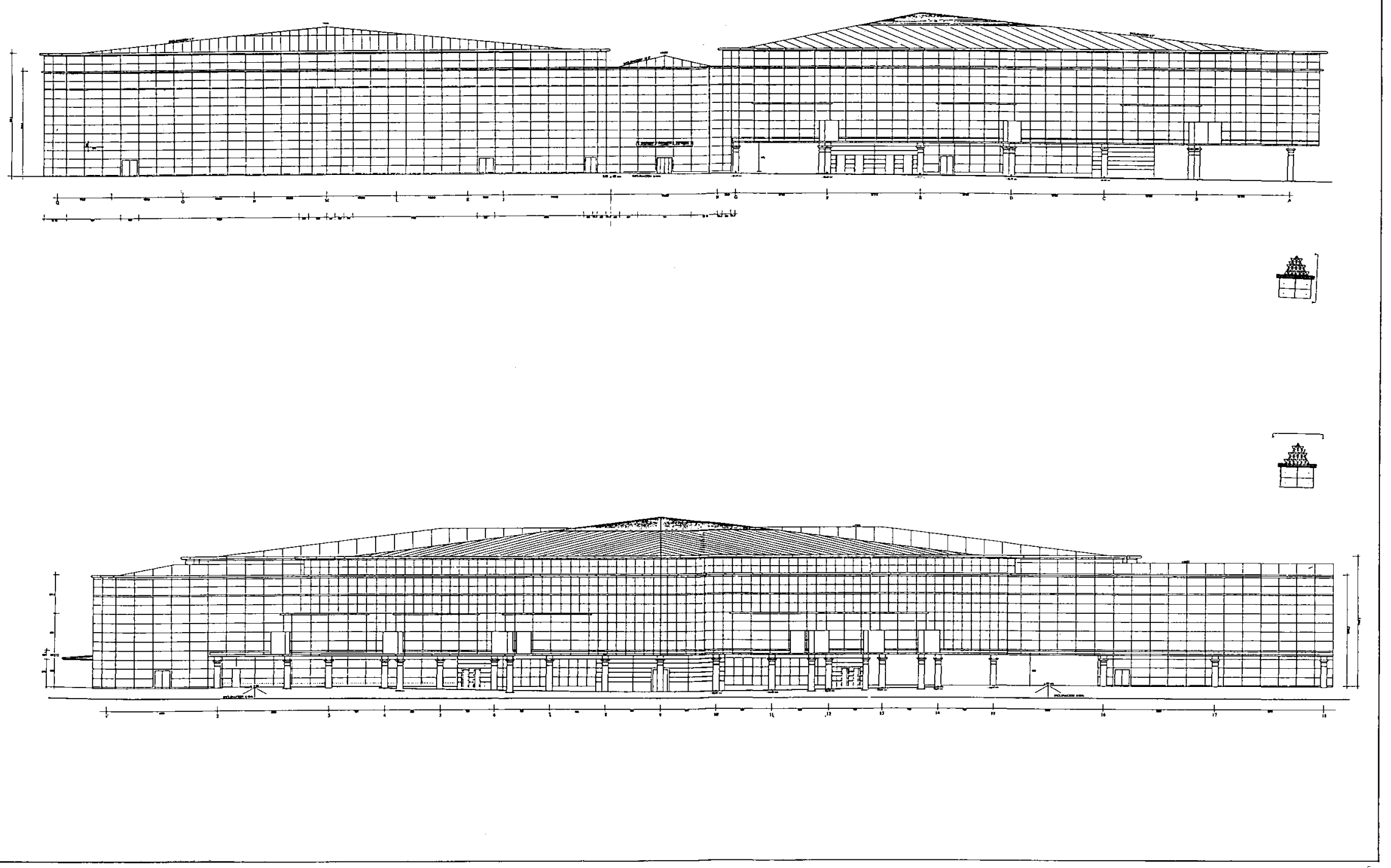

Fachadas terminal internacional 


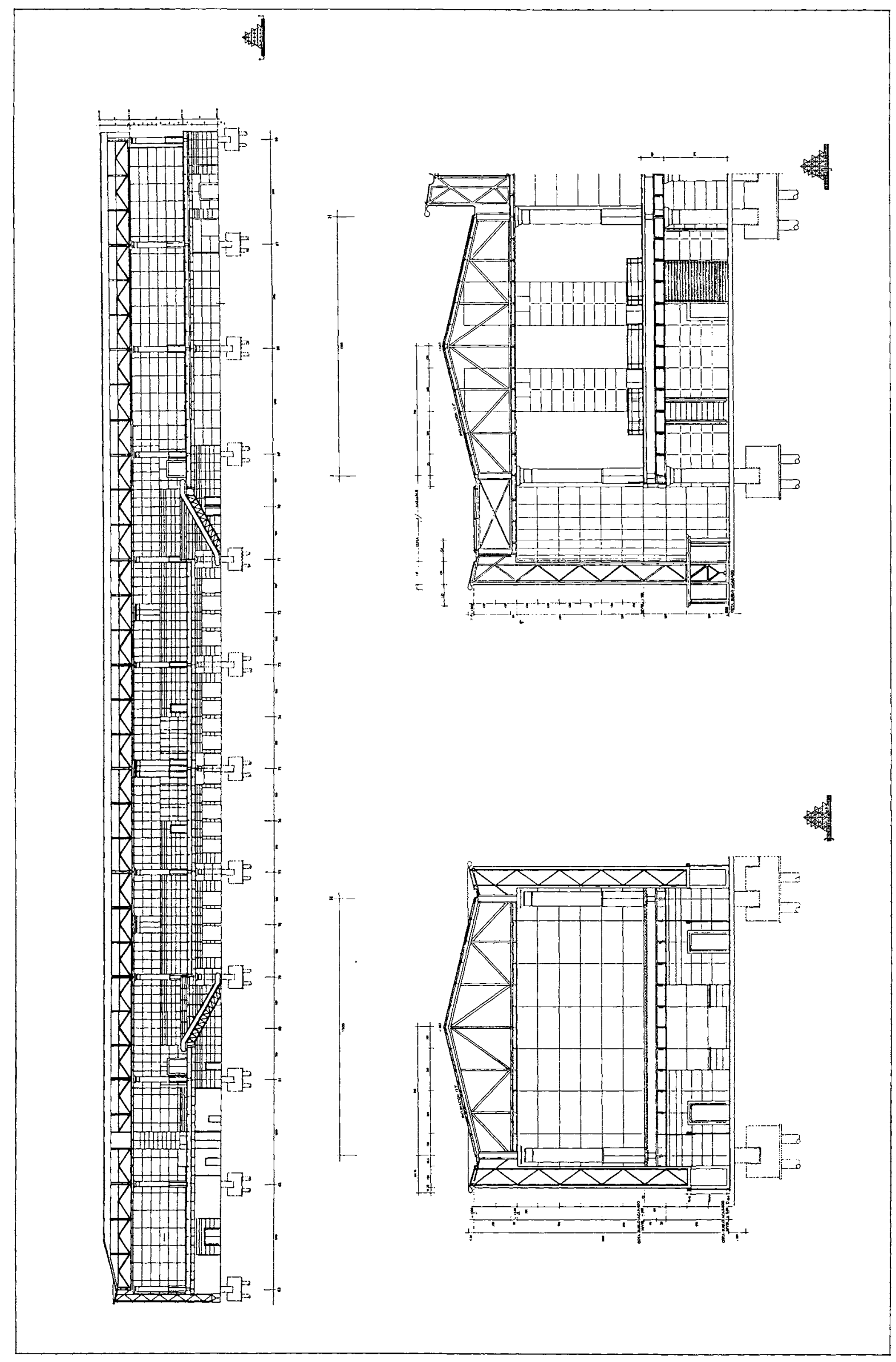




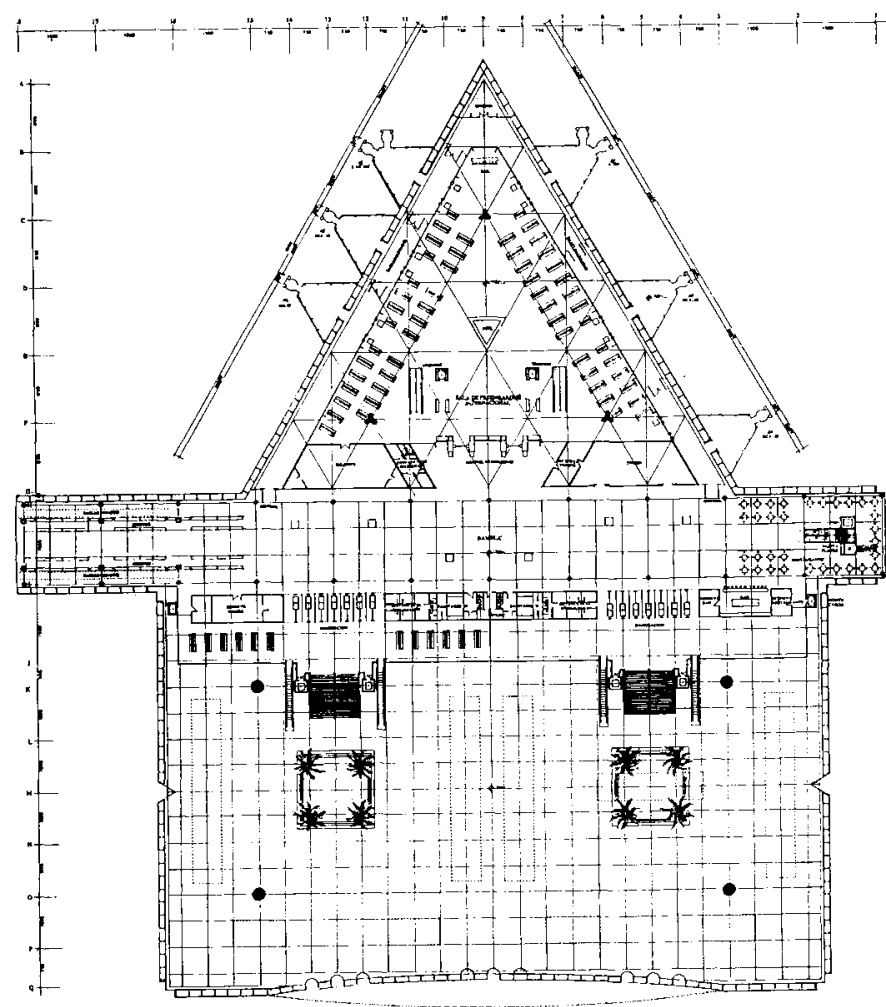

Terminal internacional. Planta alta.

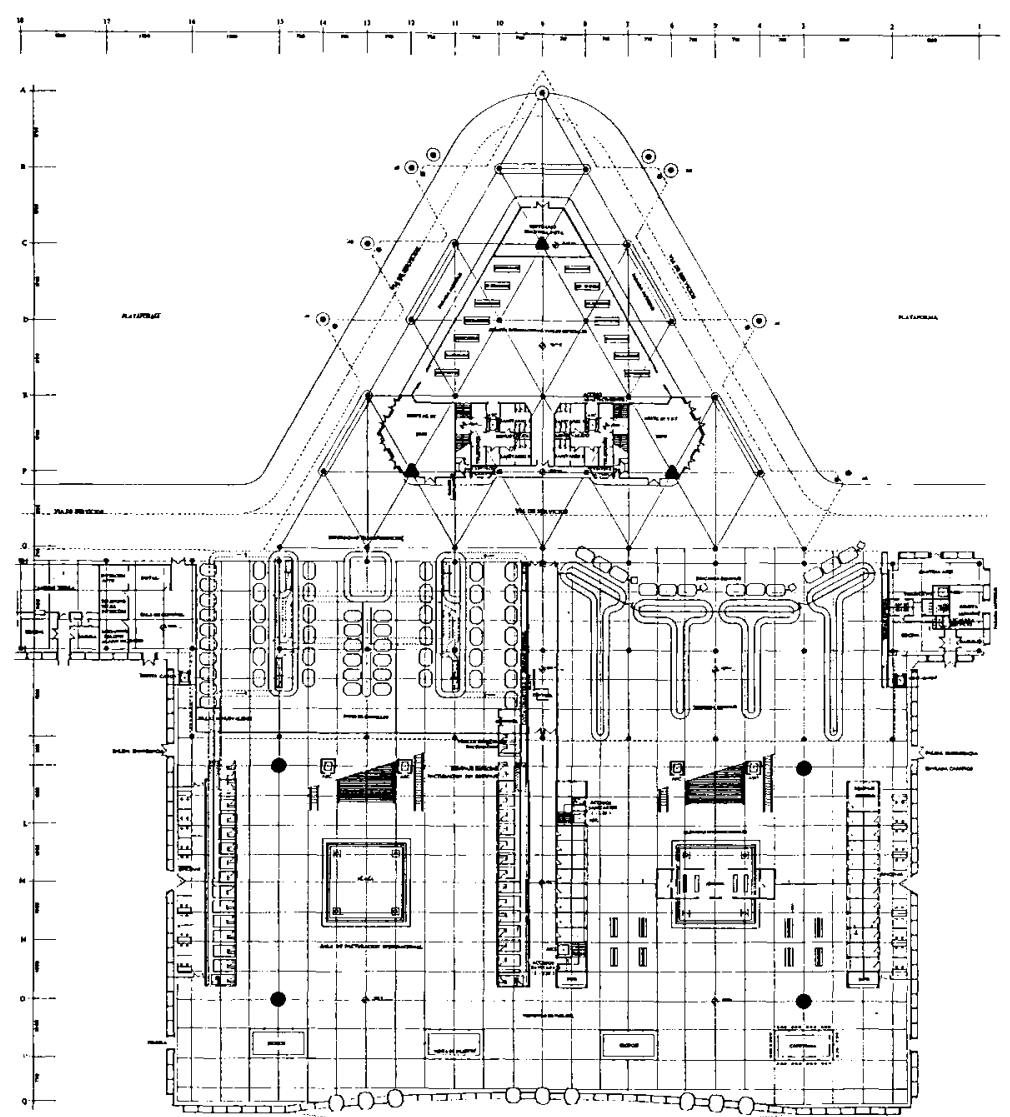

Terminal internacional. Planta baja. 


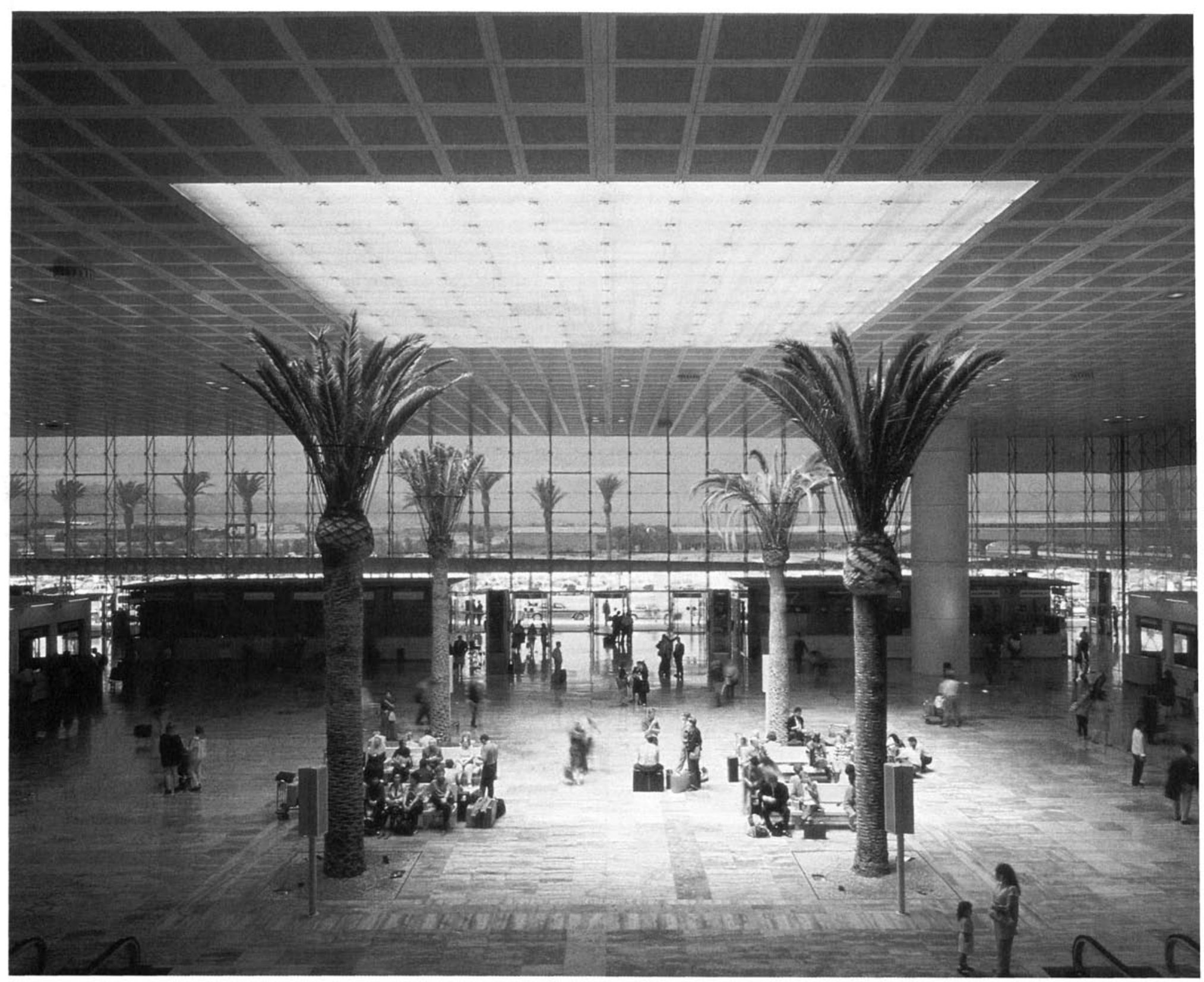

La solución lineal, parcialmente compuesta a priori por la situación de la terminal de carga y del bloque técnico, se ve reforzada con un elemento de marcado carácter lineal en forma de calle peatonal elevada que agrupará los elementos modulares, servirá de separación entre los lados tierra y aire y supondrá una divisón física entre pasaje nacional e internacional.

La fachada aire será completamente nueva y tapará el edificio existente. Los cuatro módulos de embarque albergarán las salas de preembarque. En espera de la Ilamada de embarque, el pasajero tendrá a su disposición servicios tales como bares, tiendas, etc. Estos módulos tendrán una galería acristalada en su perímetro que servirá de salida a los pasajeros que llegan. Es una división transparente que permite separar los flujos de llegadas y salidas y que, junto a un control de pasa. portes y aduanas situado en la calle elevada, cubrirá todas las posibilidades de tránsito en el Aeropuerto.
La calle elevada es la espina dorsal del proyecto, a través de la cual transitarán los pasajeros en dirección tierra o aire. Equipada con comercios y kioscos, se configura linealmente, al modo de las Ramblas de BarceIona. Los pasajeros apresurados podrán acceder a ella desde varias puertas y cruzarla rápidamente para embarcar. La simplicidad de su estructura elimina la necesidad de una señalética demasiado compleja.

El nuevo edificio estará dotado de una doble piel de vidrio y soportado por columnas de hormigón arquitectónico. El Atrium central será un espacio único y grandioso, pavimentado con mármol rojo, desde cuya entrada la vista podrá abarcar en su totalidad el conjunto del interior del edificio. El techo, de $120 \times 80 \mathrm{~m}$, aproximadamente, se apoyará sobre cuatro grandes columnas.

Peter Hodgkinson Barcelona, abril 1990 

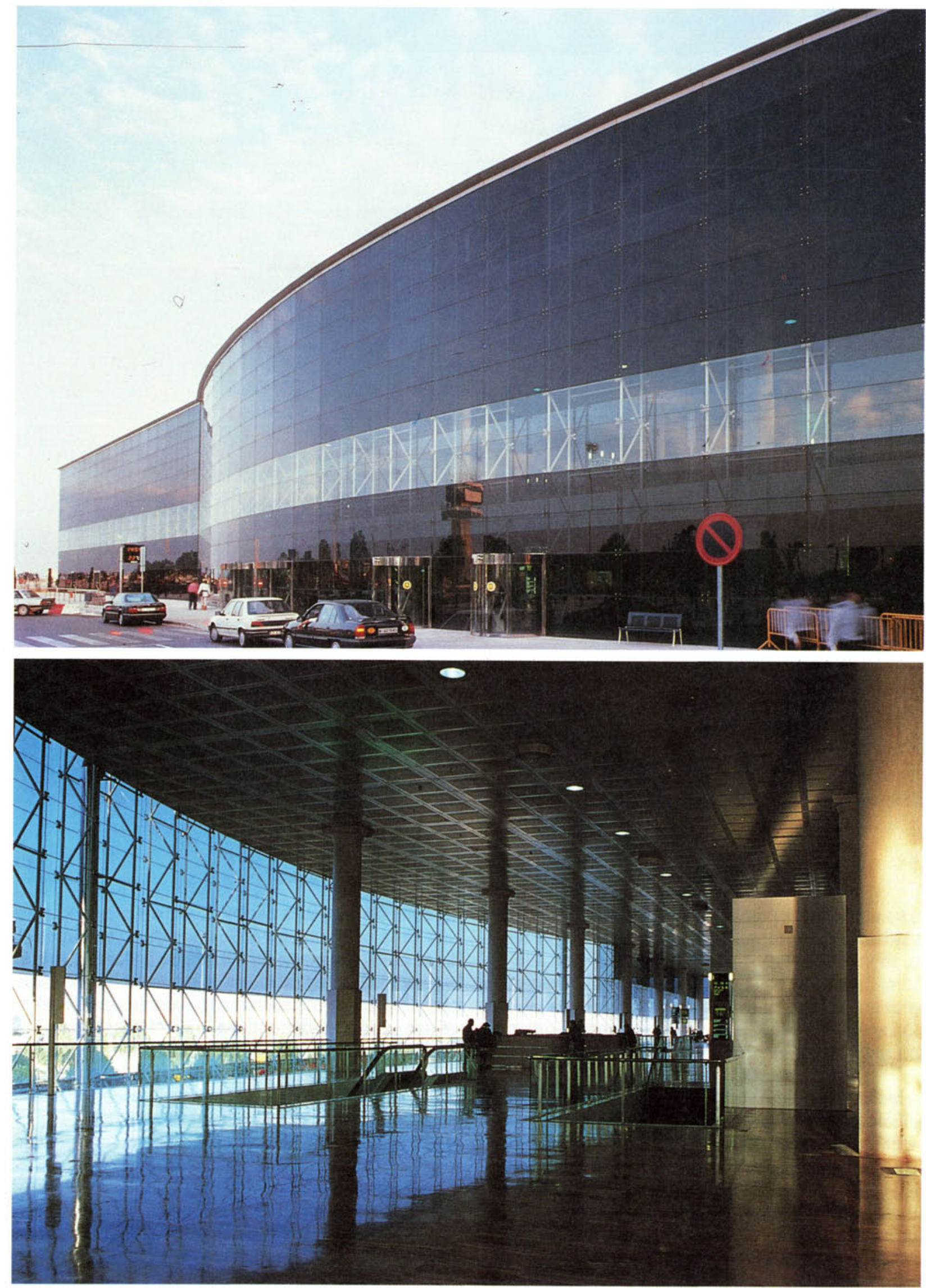

Puente aéreo 


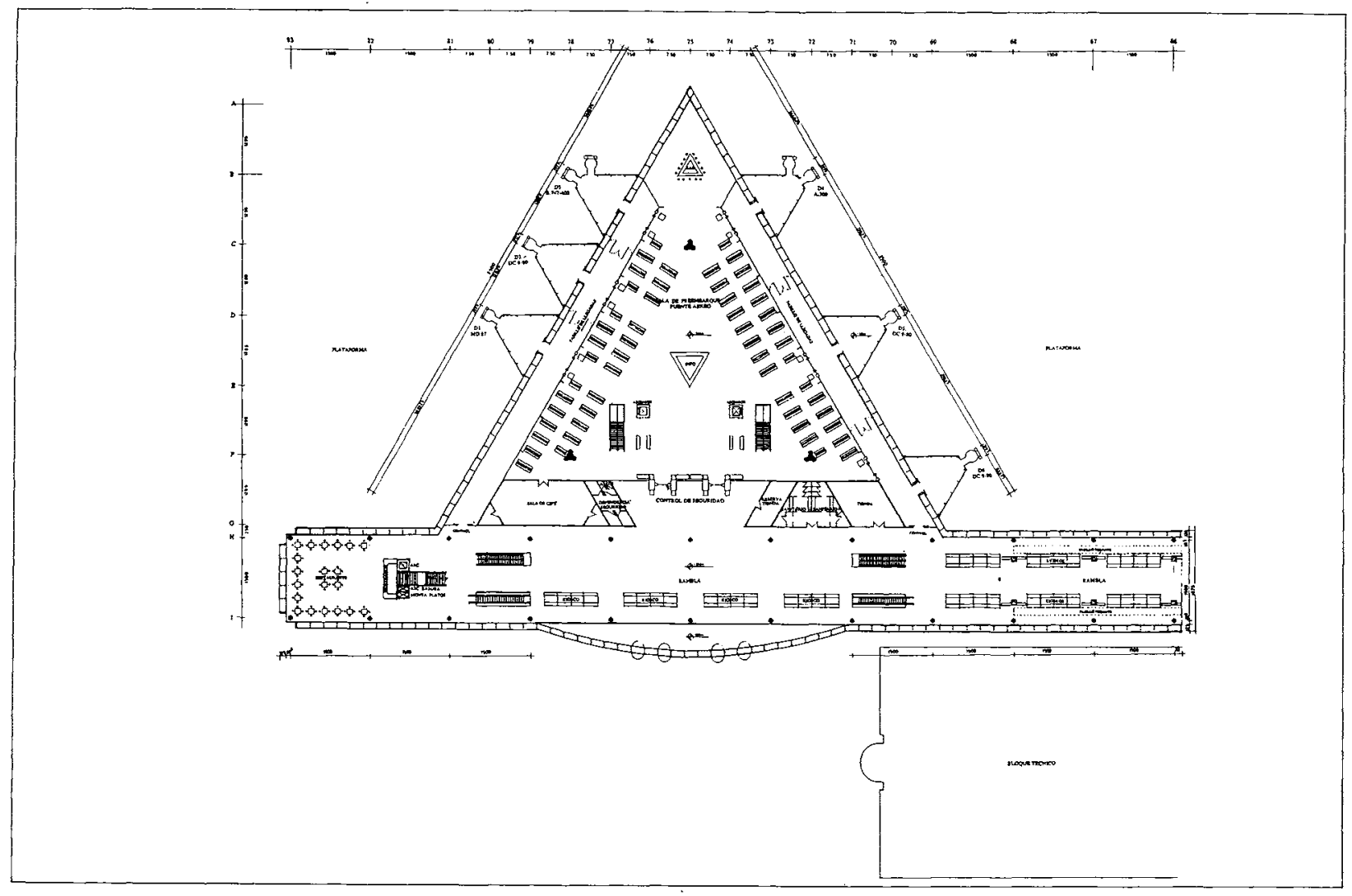

Planta alta Puente aéreo.

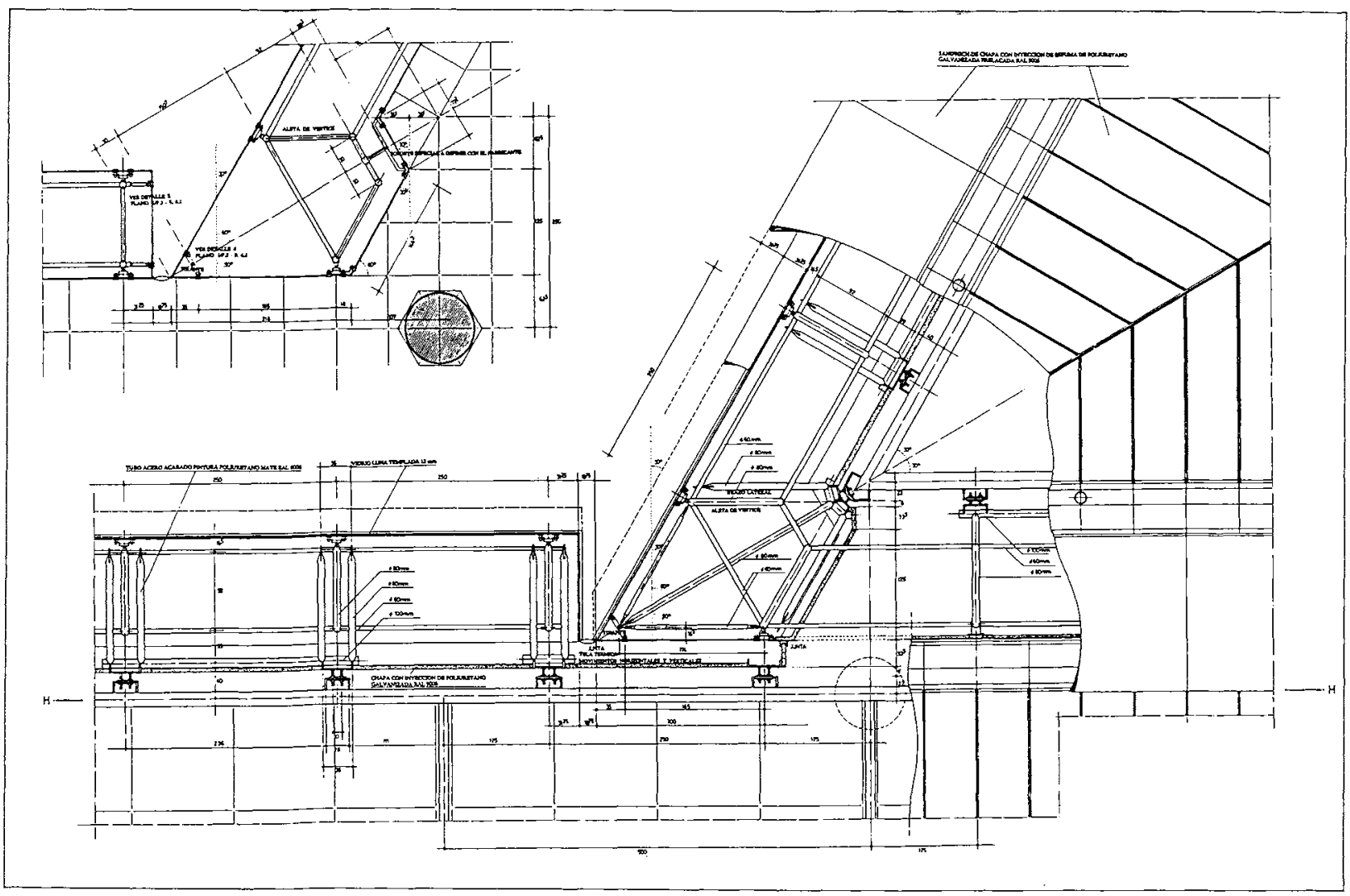

Detalle encuentro. Módulo de preembarque con rambla. 


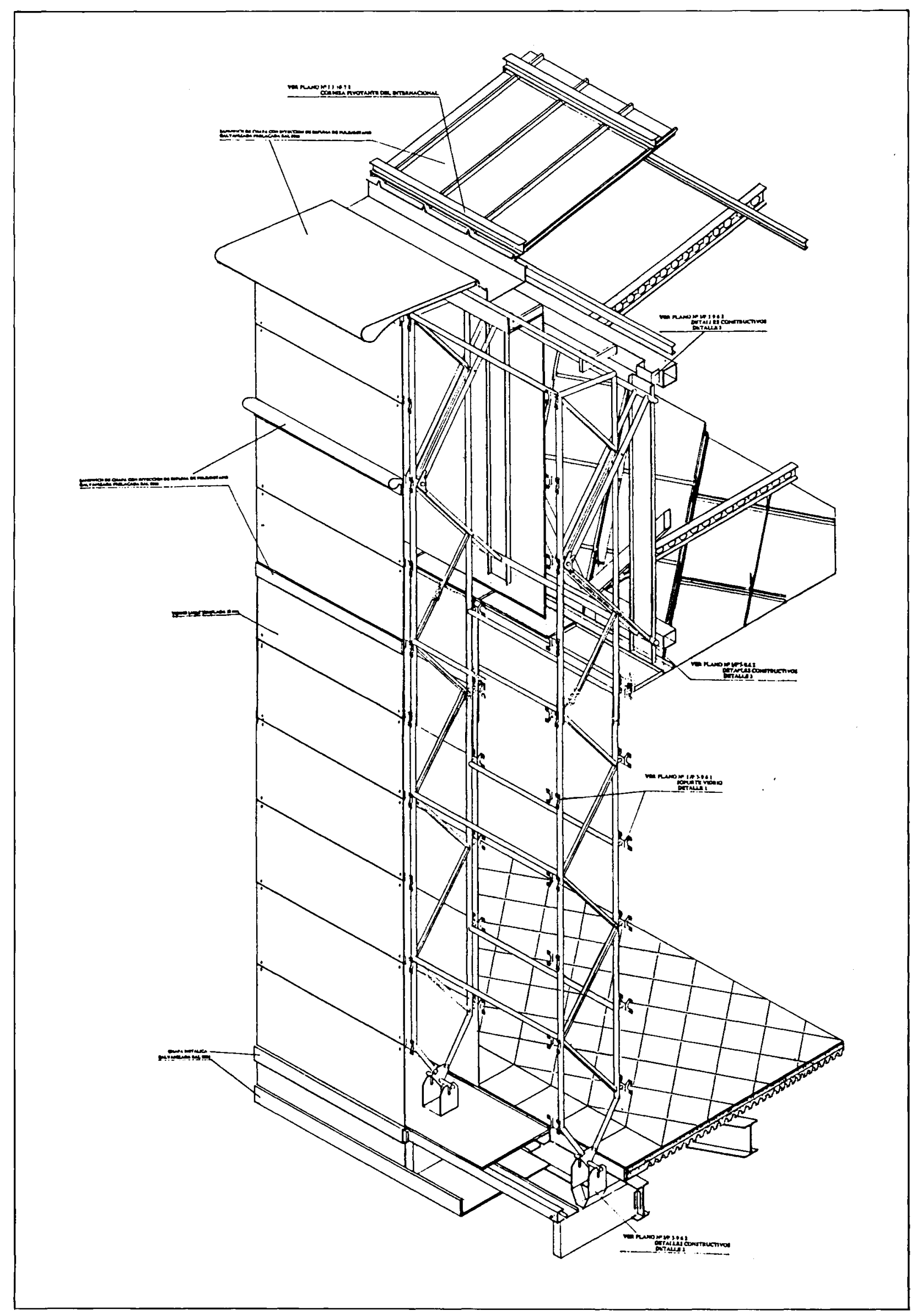



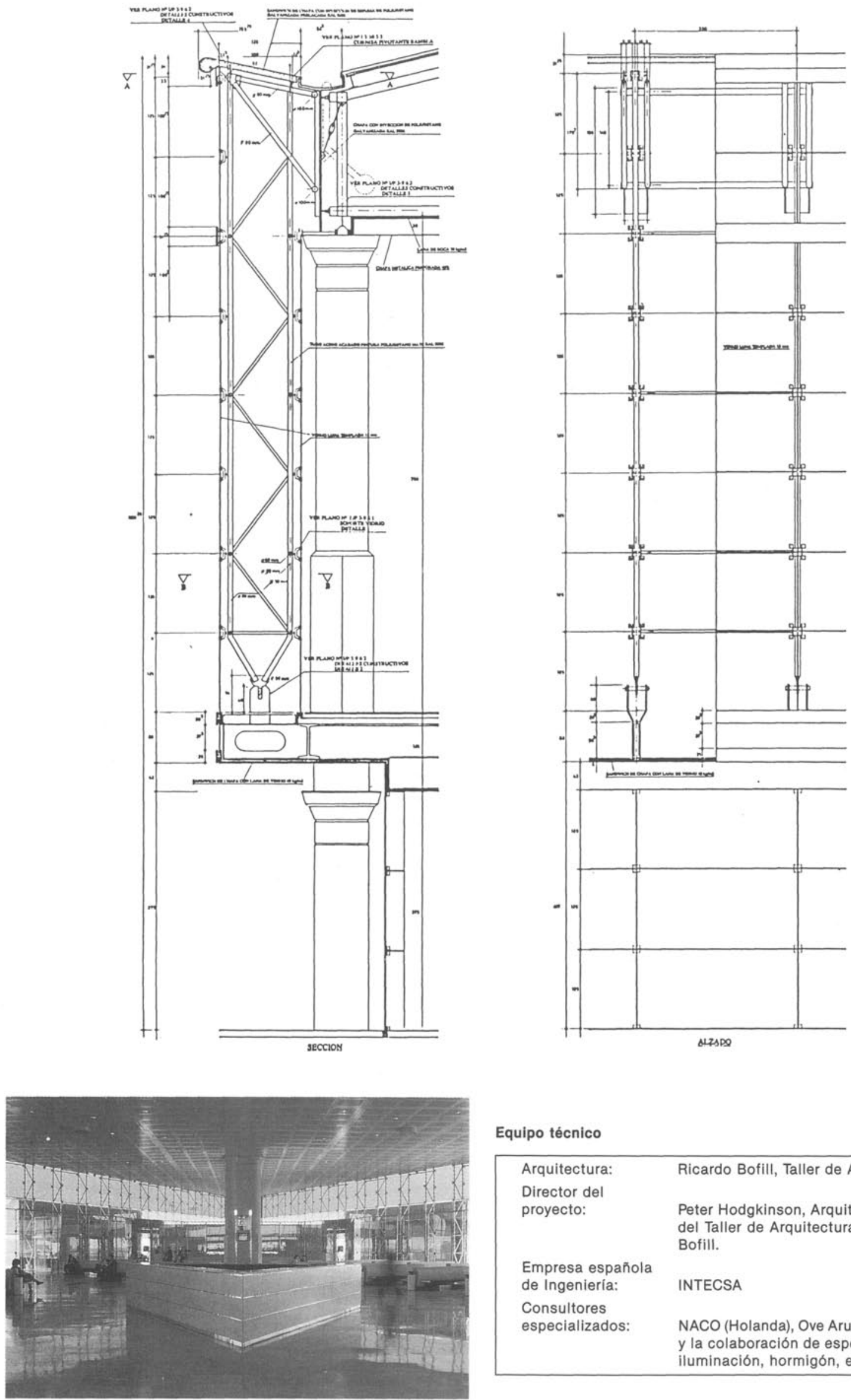

\section{Equipo técnico}

\begin{tabular}{ll|}
$\begin{array}{l}\text { Arquitectura: } \\
\text { Director del } \\
\text { proyecto: }\end{array}$ & Ricardo Bofill, Taller de Arquitectura. \\
$\begin{array}{l}\text { Empresa española } \\
\text { de Ingenieria: }\end{array}$ & $\begin{array}{l}\text { Peter Hodgkinson, Arquitecto Partner } \\
\text { Bel Taller de Arquitectura de Ricardo }\end{array}$ \\
$\begin{array}{l}\text { Consultores } \\
\text { especializados: }\end{array}$ & $\begin{array}{l}\text { INTECSA } \\
\text { y la colaboración de especialistas en } \\
\text { iluminación, hormigón, etc. }\end{array}$ \\
\hline
\end{tabular}

